\title{
Polymorphism of PfATPase in Niger: detection of three new point mutations
}

\author{
Maman Laminou Ibrahim*1, Nimol Khim², Hassane Hadiza Adam¹, \\ Frédéric Ariey ${ }^{2}$ and Jean-Bernard Duchemin ${ }^{1}$
}

\begin{abstract}
Address: ${ }^{1}$ Centre de Recherche Médicale et Sanitaire (CERMES), BP 10887 Niamey, Niger and ${ }^{2}$ Unité d'épidémiologie moléculaire, Institut Pasteur du Cambodge, 5 Boulevard Monivong, BP 983, Phnom Penh, Cambodia

Email: Maman Laminou Ibrahim* - lamine@cermes.ne; Nimol Khim - knimol@pasteur-kh.org; Hassane Hadiza Adam - hadiza1@yahoo.fr; Frédéric Ariey - fariey@pasteur-kh.org; Jean-Bernard Duchemin - duchemin@pasteur.fr

* Corresponding author
\end{abstract}

Published: 18 February 2009

Malaria Journal 2009, 8:28 doi:10.1 186/1475-2875-8-28

This article is available from: http://www.malariajournal.com/content/8/I/28

(C) 2009 lbrahim et al; licensee BioMed Central Ltd.

This is an Open Access article distributed under the terms of the Creative Commons Attribution License (http://creativecommons.org/licenses/by/2.0), which permits unrestricted use, distribution, and reproduction in any medium, provided the original work is properly cited.
Received: I August 2008

Accepted: 18 February 2009

\begin{abstract}
Background: Plasmodium falciparum resistance to drugs remains a major public health issue in Niger. The therapeutic failure index for chloroquine and sulphadoxine-pyrimethamine are, respectively $20 \%$ and $21.9 \%$. In December 2005, the National Malaria Control Programme promoted the use of artemisinin combination therapy (ACT) as first-line treatment of the uncomplicated malaria cases. Recently, studies have shown a relationship between the SERCA PfATPase6 gene and artemisinin efficacy, and pointed it out as a potential molecular marker for resistance. The goal of this work was to describe the baseline polymorphism of PfATPase6 gene in Niger, at a time when the national implementation of the ACT policy had just begun.
\end{abstract}

Materials and methods: The DNA polymorphism of the PfATPase6 gene of 87 P. falciparum samples from Niger was analysed by sequencing. The links between the mutation occurrence and environment and human host factors were tested by bivariate analysis.

Results: The P. falciparum PfATPase6 gene presented polymorphisms at codons 537, 56I, 569, 630, 639, 716 levels. All the mutations found were rare, except the PfATPaseN569K found in $17.2 \%$ of samples. No associated factor has been observed.

Conclusion: The $P$. falciparum PfATPase gene is polymorphic at the 569 codon. As ACT is getting more and more used, the PfATPase6 gene polymorphism needs to be monitored in association with phenotypic - in vivo and/or in vitro - drug efficacy tests.

\section{Background}

For many diseases, the history of anti-infectious drugs shows us that the resistance to treatment does appear after a more or less long time. This is the case for HIV, tuberculosis and, in this case, malaria [1]. The World Health Organization (WHO) recommends the use of therapeutic combination with artemisinin derivatives for a better effi- cacy and to delay the occurrence of resistance by exploiting the synergic and/or additive properties of the constituent drugs [2]. The pfATPase is an ATPase-dependent ionic pump from the Plasmodium endoplasmic reticulum membrane related to cations transport. The artemisinin and derivatives should negatively regulate this cationic pump [3]. Until recently, only six SNPs of PfAT- 
Pase were known $[4,5]$. The pfATPase6S769N mutation has been found strongly associated with artemether high IC50s in French Guyana [4] and has been proposed as a molecular marker of resistance against artemisinin. The Xenopus model [6] and docking simulation [7] suspected the 263 codon to be involved in the binding of artemisins to PfATPase6. Noting that this mutation site was never found involved in field studies, Data regarding sequences of African samples reported several mutation points: Jambou and et al [4] and Ferreira et al [5], respectively, sequenced 16 Senegalese samples and eight samples from Sao Tomé. Cojean et al [8] reported sequencing partial results of 154 samples, mainly from West Africa. From these three studies, only six mutation points were found. Recently, Dhalstrom et al [9] added the results of sequences of 345 East African and 10 West African samples, increasing the number of known SNPs to 33. Among these, three SNPs were found with a higher than 5\% percentage of mutations: the codons H431K, N569K and A630S.

In Niger, the resistance of Plasmodium falciparum to treatment is a major public health issue. At the beginning of this century, a $20 \%$ therapeutic failure index for chloroquine has been found among children under five years of age $[10,11]$. Molecular monitoring of treatment efficacy showed $45.7 \%$ of pfcrtK76T and $60.2 \%$ of pdhfrS108N [12] at the Niamey National Hospital. In the Niger Valley, these molecular markers turned out having respective prevalences of $50.8 \%$ and $57.7 \%$ [13]. Furthermore, a DNA-microarray study, targeting $34 \mathrm{P}$. falciparum resistance-associated SNPs and including PfATPase codons, showed a clear increase of resistance to chloroquine and to sulphadoxine/pyrimethamine over a four-years period [14]. In December 2005, Niger has switched as its firstline treatment policy for uncomplicated cases of malaria to the use of artemisinin-based combination therapy (ACT). Having started in 2006, the implementation has now reached the whole country. The main goal of the study, performed at a time when the national implementation of the ACT policy had just begun, was to describe the genetic polymorphism of the pfATPase gene. This should provide useful baseline data for the malaria resistance monitoring network (RSRA), [13] set-up in Niger in 2002 and included in the framework of the West African malaria resistance survey network, RAOTAP II.

\section{Methods}

\section{Samples}

Ninety two $P$. falciparum microscopy-positive samples from asymptomatic carriers have been tested. They were all coming from two villages of Sahel in south-west Niger. The two villages differed by the duration of the malaria transmission: short (two to three months) in Banizoumbou and longer (six months) in Zindarou. The samples were stratified by age (younger than 10 years old and equal and older than 10 years old), by village (Banizoumbou/Zindarou), by year (2003/2006) and by parasitaemia classes (below 1,000 parasites/ $\mu \mathrm{l}$ and above 1,000 parasites/ $\mu \mathrm{l})$. Ethical clearance was obtained from the National Ethics Committee of Niger.

\section{DNA extraction}

The DNA from the finger prick blood dried on filter cards was extracted in 96 well-plates by resin (Instagen). Briefly, dried red blood cells were first treated by lysis buffer HBS $1 \% /$ saponine $10 \%$ (HEPES $100 \mathrm{mM}, \mathrm{NaCl} 1.4 \mathrm{M}, \mathrm{KCl}$ $100 \mathrm{mM}$ ) and washed three times. The parasites pellets have been heated $\left(56^{\circ} \mathrm{C}\right.$ then $\left.90^{\circ} \mathrm{C}\right)$ with $200 \mu$ lof Instagen resin. Finally the DNA was purified by centrifugation during 20 minutes.

\section{PCR amplification and sequencing}

A nested PCR allowed the amplification of a portion of the PfATPase gene. The primary PCR allows the production of $896 \mathrm{pb}$ amplicon with primers P17.1 for 5'TGGATCAATAATACCTAATCCACCTA-3' and P17.1rev: 5'-AATATTGTTATTCAGA ATATGATTAT AA-3'. The nested PCR with internal primers P17 for 5'-AGCAAATATT TTCTGTAACGATAATA-3' and P17 rev 5'-TGTTCTAATTTATAATAATCATCTGT-3' amplified a 798 pb amplicon which was sequenced in the South Korea Biotechnology Institute. Most of the mutations found in field samples were described in that zone, including codons for the cytoplasmic domain of the PfATPase6 [15].

\section{Analysis}

Data were included in a data file with EPI-INFO v. 6.0 and bivariate relations were analysed by the Chi-square or Fisher exact tests.

\section{Results \\ Samples characteristics}

Fifty percent of the 92 samples came from Zindarou and the other half from Banizoumbou. The mean age was 13 years old and the F/M sex ratio was 1.35 . The mean parasitaemia was 2,681 parasites/ $\mu$ l.

\section{Genetic polymorphism and global prevalence of mutations} Sequencing was successful in 87 samples. Genetic polymorphism was found at six codons of the PfATPase gene: $537,561,569,630,639$ and 716 . The mutation at 537 codon did not lead to any potential protein change. The five others led to protein change. Among these, two are newly described: K561N and K716R. The prevalence of the different mutations at the 537, 561, 630, 639, and 716 codons was only $1.1 \%(1 / 87)$. The mutation PfATPase N569K prevalence was $17.2 \%$ (Table 1 ). Only one sample was carrying two mutations: N569K and G639D. 
Table I: SNPs codons and occurrences

\begin{tabular}{ccc}
\hline SNPs & Codons & $\%$ \\
\hline PfATPaseD537D & GAC-GAT & $1.1 \%(\mathrm{~N}=87)$ \\
PfATPase K56IN & AAA-AAT & $1.1 \%(\mathrm{~N}=87)$ \\
PfATPaseN569K & AAT-AAA & $17.2 \%(\mathrm{~N}=87)$ \\
PfATPaseA630S & GCT-TCT & $1.1 \%(\mathrm{~N}=87)$ \\
PfATPaseG639D & GGC-GAC & $1.1 \%(\mathrm{~N}=87)$ \\
\hline
\end{tabular}

\section{Bivariate relation of PfATPase N569K according to parasitaemia, age, village and year}

Neither the parasitaemia, nor the sex, nor the age, nor the villages, nor the collection years were related to the PfATPase N569K mutation.

\section{Discussion}

This study describes for the first time a PfATPase 6 gene sequence polymorphism in Niger. It increases the number of West African samples sequences and mutations points, adding three new mutations points: 537, 561 and 716 . Among the six different observed mutations, only one, the N569K mutation, was relatively frequent $-17.2 \%$ of isolates. Dahlstrom et al [9] had also found a high prevalence of this mutation in Zanzibar (36\%) and Tanzania (29\%). This codon was out of the Menegon et al [16] studied gene zone, as were the two new found 357 and 561 mutations. The pfATPaseS769N mutation was absent in these Niger samples, as it had been shown in China [17] and in Tanzania tested either by DNA-microarrays [18] or by sequencing [9]. The pfATPaseS769N mutation has been recently described as a potential molecular marker for $P$. falciparum resistance to artemisinin [4]. The quasi-absence of this mutation in African samples [19] - since its first report, it had only been found once by Cojean et al [8] did not disprove this hypothesis. Recently, a study from Menegon et al [16], carried out a polymorphism study of PfATPase in African isolates at codons 402 and 431, which the present work did not target. In the Niger study, there was no correlation between this mutation and other factors, such as village, age or time of collection. These factors have been correlated with chloroquine and pyrimethamine resistance in previous work [14]. The same previous study checked for five PfATPase 6 gene SNPs (538, 574, 623, 683 and 769) by DNA-microarrays [20]. By DNA-microarrays, the pfATPaseA623E mutation was found in $4.7 \%$ of the Niger samples [14], but sequencing did not confirm this.

The present work showed six different mutations for 87 samples of Niger, while Dahlstrom et al found 31 among 302 samples in Zanzibar and three among 39 Tanzanian samples [9]. Menegon et al found seven mutations sites for 71 specimens from west, central and south-east Africa [16], including Madagascar. All these figures are compara- ble and, in a given geographical zone, such molecular variation has to be linked with the sampling effort, the number of samples, but also of sequenced base pairs in a given genomic area.

\section{Conclusion}

The present work did not show the S769N mutation, presently candidate as a molecular marker for artemether resistance. However, the molecular diversity of PfATPG seems more pronounced than previously demonstrated. The variable genetic background needed for the artemisinin-driven selection of resistant variants could be present in Africa. At a time when almost all African countries have adopted artemisinin derivatives as first-line treatment, the molecular monitoring of the PfATPG gene is of prior importance. The baseline data established before the ACT implementation will support ulterior comparison. Among the highlighted mutations, the N569K mutation presents notable occurrences both in West and East Africa. Future functional studies, such as docking simulation and binding affinity, may be useful for prediction of the impact of the diverse mutations and the design of future molecular monitoring tools supporting the national control programmes.

\section{Competing interests}

The authors declare that they have no competing interests.

\section{Authors' contributions}

MLI carried out the molecular genetic studies and drafted the first manuscript version. HHA participated to field work and DNA extraction. NK participated in the sequence alignment. FA and JBD conceived the study, participated in its design and coordination and elaborated the final version of manuscript. All authors read and approved the final manuscript.

\section{Acknowledgements}

Thanks to the Banizoumbou and Zindarou inhabitants who participated to this work. We are grateful to the Ministry of Health and the National Malaria Control Programme (PNLP). We are thankful to the technicians of the CERMES Parasitology Unit and the Institute Pasteur of Cambodia. Field studies and sampling were funded by the WHO and the African Monsoon Multidisciplinary Analysis (AMMA). Genotyping was funded by the Institute Pasteur.

\section{References}

I. OMS: L'utilisation des antipaludiques. OMS, 13-17 November 2000, Rapport $\mathrm{N}^{\circ} 33$.

2. OMS: Les combinaisons thérapeutiques antipaludiques. OMS, 4-5 April 2000. Rapport $N^{\circ} 35$.

3. Kimura M, Tanabe K, Krisna S, Tsuboi T, Ogura H: Gametocyte dominant expression of a novel type ATPase in Plasmodium yoelii. Mol Biochem Parasitol 1999, 104:331-336.

4. Jambou R, Legrand E, Niang Mackhtar, Khim N, Mercereau-Puijalon $\mathrm{O}$ : Resistance of Plasmodium falciparum field isolates to in vitro artemether and point mutation of SERCA-type PfATPase6. Lancet 2005, 366:1960-1963.

5. Ferreira ID, Lopes D, Martinelli A, Ferreira C, do Rosário VE, Cravo $P$ : In vitro assessment of artesunate, artemether and amodi- 
aquine susceptibility and molecular analysis of putative resistance-associated mutations of Plasmodium falciparum from São Tomé and Príncipe. Trop Med Int Health 2007, 1 2:353-362.

6. Eckstein-Ludwig U, Webb RJ, Van Goethem ID, East JM, Lee AG, Kimura M, O'Neill PM, Bray PG, Ward SA, Krishna S: Artemisinins target the SERCA of Plasmodium falciparum. Nature 2003, 424:957-961.

7. Jung M, Kim H, Nam KY, No KT: Three-dimensional structure of Plasmodium falciparum Ca2+-ATPase(PfATP6) and docking of artemisinin derivatives to PfATP6. Bioorg Med Chem Lett 2005, I 5:2994-2997.

8. Cojean S, Hubert V, Le Bras J, Durand R: Resistance to dihydroartemisinin. Emerg Infect Dis 2006, I 2:1798-1799.

9. Dahlström S, Veiga MI, Ferreira P, Mårtensson A, Kaneko A, Andersson $B$, Björkman A, Gil JP: Diversity of the sarco/endoplasmic reticulum $\mathrm{Ca}(2+)$-ATPase orthologue of Plasmodium falciparum (PfATP6). Infect Genet Evol 2008, 8:340-345.

10. Dugelay F, Adehossi E, Adamou S, Ousmane I, Parzy D, Delmont J, Parola P: Efficacy of chloroquine in the treatment of uncomplicated, Plasmodium falciparum malaria in Niamey, Niger, in 200 I. Ann Trop Med Parasitol 2003, 97:83-86.

II. Parola $P$, Ali I, Djermakoye F, Crassard N, Bendavid C, Faugère B, Condomines C: Chloroquinosensibilité de Plasmodium falciparum à la clinique Gamkalley et à la PMI des Forces armées nigériennes (Niamey, Niger). Bull Soc Path Exot 1999, 92:317-319.

12. Ibrahim ML, Gay-Andrieu F, Adehossi E, Lacroix V, Randrianarivelojosia M, Duchemin JB: Field based evidence for the evidence for the linkage of pfcrt and pfdhfr resistant malaria genotypes and clinical profiles of severe malaria in Niger. Microbes Infect 2007, 9:599-604.

13. Ibrahim ML, Hadiza H, Konaté L, Adamou S, Duchemin JB: Réseau de surveillance moléculaire de la chimiorésistance de Plasmodium falciparum à la chloroquine et la pyriméthamine dans la vallée du fleuve Niger, au Niger. Bull Soc Path Exot 2008, I0I:47-49.

14. Ibrahim ML, Nimol K, Konaté L, Hassane H, Ariey F, Duchemin JB: Analysis of 34 SNPs associated to Plasmodium falciparum resistance by DNA-miroarray in Niger. Malar J in press.

15. Dhitavat J, Dode L, Leslie N, Sakuntabhai A, Lorette G, Hovnanian A: Mutations in the sarcoplasmic/endoplasmic reticulum $\mathrm{Ca2+}$ ATPase isoform cause Darier's disease. J Invest Dermatol 2003, 1 21:486-489.

16. Menegon M, Sannela AR, Majori G, Severini C: Detection of novel point mutation in the Plasmodium falciparum ATPase candidate gene for resistance to artemisinin. Parasitol Int 2008, 57:233-235

17. Zhang G, Guan Y, Zheng B, Wu S, Tang L: No PfATPaseS769N mutation found in Plasmodium falciparum isolates from China. Malar J 2008, 7:122.

18. Mugittu K, Genton B, Mshinda H, Beck HP: Molecular monitoring of Plasmodium falciparum resistance to artemisinin in Tanzania. Malar J 2006, 5:126.

19. Afonso A, Hunt P, Cheesman S, Alves A, Cravo P: Malaria parasites can develop stable resistance to artemisinin but lack mutations in candidate gene ATPase 6, tctp, mdrl and cgl0. Antimicrob Agents Chemother 2006, 50:480-489.

20. Crameri A, Marfurt J, Mugittu K, Maire N, Beck HP: Rapid microarray-based method for monitoring of all currently know single nucleotide polymorphisms associated with parasite resistance to antimalaria drugs. J Clin Microbiol 2007, 45:3685-399I.

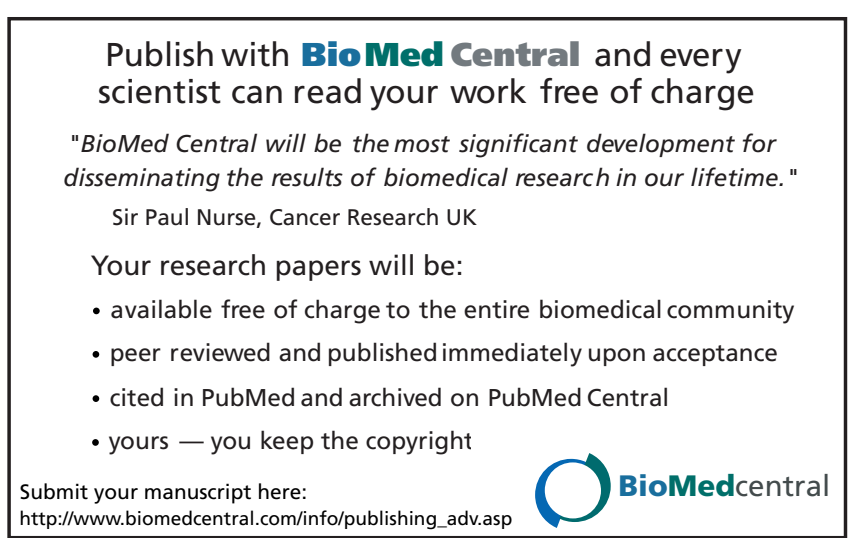

